\title{
Indirubin-3'-monoxime promotes autophagic and apoptotic death in JM1 human acute lymphoblastic leukemia cells and K562 human chronic myelogenous leukemia cells
}

\author{
MING-YANG LEE ${ }^{1,4}$, YI-WEN LIU ${ }^{3}$, MING-HO CHEN ${ }^{2}$, JIN-YI WU ${ }^{3}$, \\ HSING-YING $\mathrm{HO}^{3}$, QWA-FUN WANG ${ }^{3}$ and JING-JING CHUANG ${ }^{3}$
}

\begin{abstract}
Departments of ${ }^{1}$ Hematology and Oncology, and ${ }^{2}$ Chinese Medicine, Ditmanson Medical Foundation Chia-Yi Christian Hospital, Chiayi; ${ }^{3}$ Department of Microbiology, Immunology and Biopharmaceuticals, National Chiayi University, Chiayi; ${ }^{4}$ Department of Medical Laboratory Science and Biotechnology, Chung Hwa University of Medical Technology, Tainan, Taiwan, R.O.C.
\end{abstract}

Received December 18, 2012; Accepted February 8, 2013

DOI: 10.3892/or.2013.2334

\begin{abstract}
Indirubin is the active component of Dang Gui Long Hui Wan, a traditional Chinese herbal medicine used as therapy for chronic myelogenous leukemia (CML). In clinical studies, indirubin seldom caused major side-effects. However, the functional effect of indirubin on acute lymphoblastic leukemia (ALL) is unclear. Therefore, we investigated the effects of indirubin-3'-monoxime (I3M) on the ALL cell line JM1 and the CML cell line K562 (control). The anti-leukemia effects and mechanisms of I3M were similar on ALL and CML cells. I3M significantly and dose-dependently decreased cell viability. The G2/M cell cycle phase was arrested and the sub-G1 proportion was relatively increased. In addition, caspase- 3 activation led to poly(ADP-ribose) polymerase (PARP)-1 cleavage and the progression of apoptosis. Notably, I3M induced autophagy. However, I3M had no effect on necrosis in either cell line. We specifically found that I3M only marginally affected the survival of primary mature lymphocytes, and was not cytotoxic to granulocytes. Since I3M induced apoptosis and autophagy in human lymphocytic leukemia cells and caused few side-effects in healthy lymphocytes and granulocytes, I3M may be useful for clinical anti-ALL therapy.
\end{abstract}

\section{Introduction}

The current clinical treatments for adults with acute lymphoblastic leukemia (ALL) yield positive initial responses, but treatment-related mortality (TRM) is common and the risk

Correspondence to: Dr Jing-Jing Chuang, Department of Microbiology, Immunology and Biopharmaceuticals, National Chiayi University, 300 Syuefu Road, Chiayi 600, Taiwan, R.O.C.

E-mail: yihyeh@mail.ncyu.edu.tw

Key words: indirubin-3'-monoxime, acute lymphoblastic leukemia, apoptosis, cell cycle arrest, autophagy of a relapse is relatively high. The cure rate of adult ALL scarcely exceeds $40 \%$, and TRM is between 5 and $10 \%$ (1). Long periods of hospitalization and serious morbidity for ALL are common. Leukemic relapse in adult ALL remains a major therapeutic problem, and it has no suitable salvage therapy with low side-effects, not even hematopoietic stem cell transplantation, which produces both short- and long-term toxicity $(2,3)$. It is, therefore, critical to develop new therapeutics for adult ALL treatment.

Indirubin is the active ingredient of Dang Gui Long Hui Wan, from a mixture of herbal medicines customarily used in traditional Chinese medicine to treat chronic myelocytic leukemia (CML) (4). Clinical trials in China $(5,6)$ showed that indirubin causes almost no toxicity in the liver, kidneys, or bone marrow. It has also been reported that the indirubin derivative acts a potent inhibitor of cyclin-dependent kinases (CDKs) such as CDK1 and CDK2 $(4,7,8)$. The indirubininduced arrest of the G1 or G2/M phase of the cell cycle in a variety of cultured cell types, including chronic leukemia cells (K562), has also been studied $(4,9,10)$. Additionally, indirubin and its derivatives induce apoptosis in a variety of human tumor cells: breast cancer $(7,11)$, melanoma $(12,13)$, oral-area carcinoma $(9,10,14)$, lung cancer $(10)$ and promyelocytic leukemia (HL-60) (15) cells. Nevertheless, the functional effect of indirubin on ALL remains unknown.

In the present study, we specifically focused on the cytotoxicity of indirubin-3'-monoxime (I3M) and its mechanism of cell death in B cell lymphoblast leukemia cells and chronic myeloid leukemia cells. We also investigated the hematotoxicity of I3M by analyzing the survival of normal human granulocytes and lymphocytes.

\section{Materials and methods}

Isolation of lymphocytes and granulocytes. Buffy coats from healthy donors were obtained from the Tainan Blood Center, Taiwan Blood Services Foundation. Approval was obtained from the Chiayi Christian Hospital Institutional Review Board for these studies. Informed consent was obtained according 
to the Declaration of Helsinki. Peripheral blood mononuclear cells (PBMCs) were isolated using density gradient centrifugation (Ficoll-Paque; GE Healthcare Bio-Sciences AB, Uppsala, Sweden). After washing, the cells were incubated in Petri dishes at $37^{\circ} \mathrm{C}$ in an atmosphere of $5 \% \mathrm{CO}_{2}$ for $90 \mathrm{~min}$. Non-adherent cells were separated from adherent monocytes by moderate aspiration and used as lymphocytes. Flow cytometry (FACSan; BD Biosciences, Palo Alto, CA, USA) showed that $>85 \%$ of this lymphocyte population stained positive for CD3-antibody (data not shown). Granulocytes were isolated using the MACS $^{\circledR}$ (Miltenyi Biotec, Auburn, CA, USA) online general protocol. Briefly, after the PBMCs had been isolated, the thin, white cell-layer over the erythrocytes was collected and washed in Dulbecco's phosphate-buffered saline (DPBS). To lyse the remaining red blood cells, they were incubated with three times the volume of lysis buffer $\left[155 \mathrm{mM} \mathrm{NH}_{4} \mathrm{Cl}, 10 \mathrm{mM} \mathrm{KHCO}_{3}\right.$ and $0.1 \mathrm{mM}$ EDTA (pH: 7.3)] for $5 \mathrm{~min}$ at room temperature. After they had been centrifuged and washed, the granulocytes were finally obtained. The granulocyte population used in the experiments was CD45-antibody-positive. Flow cytometry showed that the percentage of granulocytes was $>88 \%$.

Cell culture. Human CML K562 and human ALL JM1 cells were obtained from the Bioresource Collection and Research Center, Taiwan. The K562 cells were cultured in Iscove's modified Dulbecco's medium (IMDM) supplemented with $10 \%$ fetal bovine serum (FBS) and $4 \mathrm{mM} \mathrm{L-glutamine} \mathrm{(Gibco/}$ Invitrogen, Grand Island, NY, USA); the JM1 cells were kept in IMDM supplemented with $10 \%$ FBS, 4 mM L-glutamine and $0.05 \mathrm{mM}$ 2-mercaptoethanol (Sigma-Aldrich, St. Louis, $\mathrm{MO}, \mathrm{USA})$ at $37^{\circ} \mathrm{C}$ in a humidified atmosphere containing $5 \%$ $\mathrm{CO}_{2}$ in air.

The primary lymphocytes and the granulocytes were cultured in RPMI-1640 medium (Gibco/Invitrogen) supplemented with $10 \%$ FBS, $2 \mathrm{mM}$ L-glutamine and penicillin $(100 \mathrm{U} / \mathrm{ml})$ streptomycin $(100 \mu \mathrm{g} / \mathrm{ml})(\mathrm{Gibco} /$ Invitrogen) at $37^{\circ} \mathrm{C}$ in an atmosphere of $5 \% \mathrm{CO}_{2}$ in air.

Cell viability assay. The inhibitory effect of $\mathrm{I} 3 \mathrm{M}$ on cell viability was determined using a WST-1 colorimetric assay (Roche Diagnostics, Mannheim, Germany). The assay was set up in 96-well culture plates with triplicate wells for each experimental condition. JM1 cells $\left(1 \times 10^{5} /\right.$ well) and K562 cells ( $3 \times 10^{4} /$ well) were treated with a series of concentrations of I3M (7.5-35 $\mu \mathrm{M})$ for 24 and $48 \mathrm{~h}$. WST-1 was then added to each well and the cells were incubated for $2 \mathrm{~h}$ at $37^{\circ} \mathrm{C}$ in the dark. This assay is based on the conversion of the tetrazolium salt 3-(4,5-dimethylthiazol-2-yl)-5-(3carboxymethoxyphenyl)-2-(4-sulfophenyl)-2-tetrazolium by mitochondrial dehydrogenase to a formazan product. The absorbance at $450 \mathrm{~nm}$ was measured using a microplate reader. Cell viability is expressed as a percentage of population growth with a standard deviation (SD) relative to that of untreated control cells. For apoptotic analyses, the cells were incubated with benzyloxycarbonyl-Val-Ala-Asp-(OMe)fluoromethylketone (Z-VAD-FMK) (Sigma-Aldrich) for $1 \mathrm{~h}$ prior to I3M treatments.

Cell cycle analysis. K562 and JM1 cells were treated with 10 or $20 \mu \mathrm{M}$ of I3M for 24 or $48 \mathrm{~h}$. After washing with PBS, the cells were fixed in cold $70 \%$ ethanol at $4^{\circ} \mathrm{C}$ for $6 \mathrm{~h}$, centrifuged at $300 \mathrm{~g}$ for $10 \mathrm{~min}$, and then stained in PBS containing $40 \mu \mathrm{g} / \mathrm{ml}$ of propidium iodide (PI) (Sigma-Aldrich) and $100 \mu \mathrm{g} / \mathrm{ml}$ of RNase A (Invitrogen) for $30 \mathrm{~min}$ at room temperature. The flow cytometer was used for cell cycle analysis. The histogram of the cell cycle distribution was then analyzed (ModFit LT; Verity Software House, Topsham, ME, USA). The percentage of cells in the subdiploid region (sub-G1) represented cells undergoing apoptotic DNA fragmentation.

Activity of caspase-3 assay. Analysis of the enzymatic activity of caspase-3 in K562 and JM1 cells was carried out using a caspase-3/CPP32 colorimetric assay kit (BioVision, Mountain

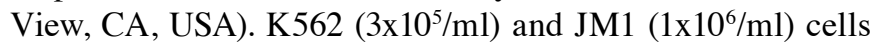
were treated with or without various concentrations of I3M for $48 \mathrm{~h}$, and were then centrifuged. Chilled cell lysis buffer $(50 \mu \mathrm{l})$ was added to the cell pellet, which was then incubated on ice for $10 \mathrm{~min}$. After the protein concentration had been analyzed, an additional $100 \mu \mathrm{g}$ of protein was mixed with $2 \mathrm{X}$ reaction buffer and DEVD-p-nitroanilide (pNA) substrate. The incubation was carried out at $37^{\circ} \mathrm{C}$ for $2 \mathrm{~h}$. This assay was based on detecting the chromophore pNA after it had been cleaved from the labeled substrate DEVD-pNA. pNA light emission was quantified using a microtiter plate at $405 \mathrm{~nm}$. The activity of caspase-3 in I3M-treated cells was determined comparing their absorbance values with those of untreated control cells.

Assessing cell necrosis. After K562 cells $\left(3 \times 10^{4}\right)$ and JM1 cells $\left(1 \times 10^{5}\right)$ had been incubated with or without various concentrations of I3M for 24 or $48 \mathrm{~h}$, their necrotic cell death was quantitatively measured by releasing lactate dehydrogenase (LDH) into the culture supernatants (CytoTox 96 ${ }^{\circledR}$ Non-Radioactive Cytotoxicity Assay kit; Promega, Madison, WI, USA). During the loss of membrane integrity and cell necrosis, LDH expression increased. The culture supernatants (50 $\mu \mathrm{l} /$ well) were transferred to an enzymatic assay plate, mixed with reconstituted substrate, and then incubated for $30 \mathrm{~min}$ at room temperature in the dark. After stop solution had been added, the absorbance was recorded at $492 \mathrm{~nm}$. Maximal LDH release occurred after the control cells had been lysed for $45 \mathrm{~min}$ at room temperature.

Western blotting for LC3-II formation, PARP-1 cleavage, and beclin-1 antibody expression. JM1 and K562 cells were treated with or without I3M for 24 and $48 \mathrm{~h}$. To assess the protein expression, the whole cell extract was harvested in lysis buffer (1\% NP-40, $0.5 \%$ sodium deoxycholate, $0.1 \%$ SDS and a protease inhibitor mixture) on ice for $20 \mathrm{~min}$. Following centrifugation, the protein concentration was analyzed using a BCA assay (Thermo Fisher Scientific, Fremont, CA, USA), and subjected to sodium dodecyl sulfate-polyacrylamide gel electrophoresis (SDS-PAGE). After the whole cell extract had undergone western blotting, the SDS-PAGE PVDF membrane was blocked with antibodies against LC3 (Novus Biologicals, Littleton, CO, USA), PARP-1/2 (H-250), or beclin-1 (Santa Cruz Biotechnology, Santa Cruz, CA, USA) and then incubated with secondary antibodies: anti-goat IgG antibody or anti-rabbit IgG antibody (Jackson ImmunoResearch, West Grove, PA, USA). Actin or $\alpha$-tubulin (Sigma-Aldrich) was used as an internal control. 
A

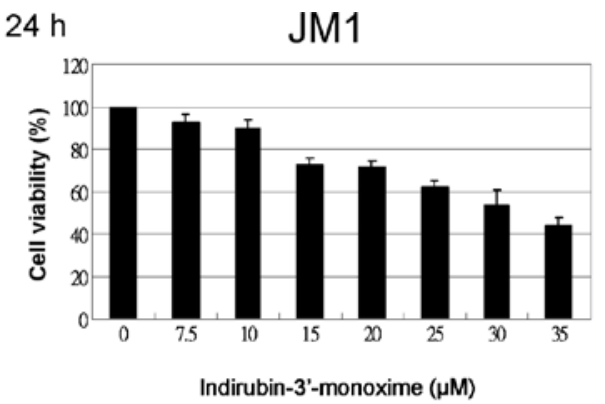

C $24 \mathrm{~h}$

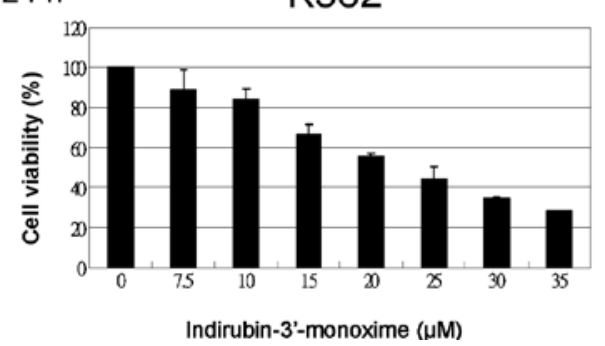

B

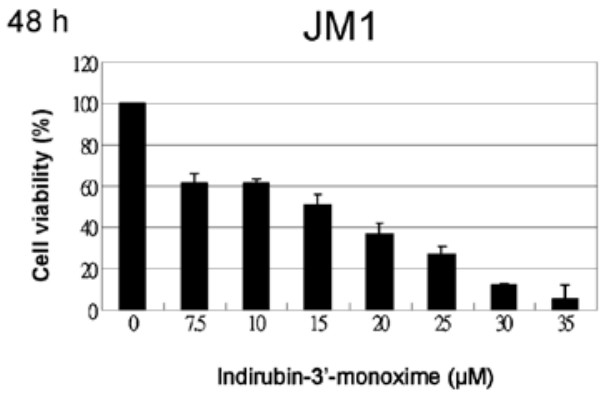

D

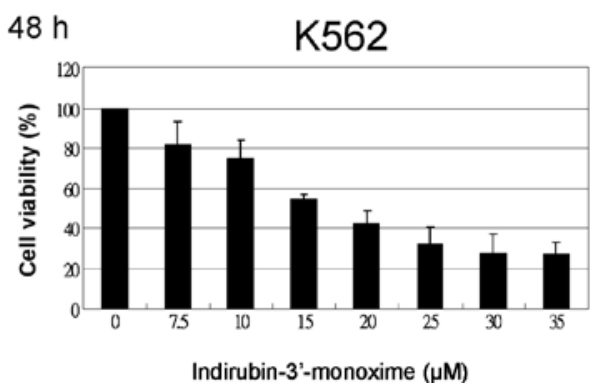

Figure 1. Cytotoxicity of indirubin-3'-monoxime (I3M) on JM1 and K562 cells. (A and B) JM1 and (C and D) K562 cells were treated with various concentrations of I3M for 24 or $48 \mathrm{~h}(\mathrm{n}=8)$. Untreated cells were the controls. Cell viability was assessed using a WST-1 assay. Data are the means \pm SD and are expressed as a percentage of control values [I3M-untreated cells (controls) $=100 \%$ ] (all treatments with $>10 \mu \mathrm{M} \mathrm{I3M}$ vs. untreated controls, $\mathrm{P}<0.05$ ).

Statistical analysis. Each experiment was repeated at least 6 times. Data are the means \pm SD. Single values represent the mean optical density (OD) value of triplicate cultures and are given as a percentage of the control (= $100 \%$ proliferation). A two-tailed Student's t-test was used for statistical analysis.

\section{Results}

I3M is cytotoxic and decreases cell viability in ALL and CML cells. A WST-1 assay of cell viability was used to determine whether I3M is cytotoxic to JM1 (ALL) cells. Differences in the antitumor effects of I3M were compared in JM1 cells and K562 (CML) cells. I3M significantly dose-dependently reduced cell viability in JM1 and K562 cells (Fig. 1). At 48 h, the $50 \%$ inhibitory concentration $\left(\mathrm{IC}_{50}\right)$ value of $\mathrm{I} 3 \mathrm{M}$ against JM1 and K562 cells was below $20 \mu \mathrm{M}$. The 48-h treatment was more cytotoxic than the $24-\mathrm{h}$ treatment, particularly in JM1 cells.

I3M arrests human JMI and $K 562$ cells in the G2/M phase of the cell cycle. To assess the effect of I3M on the cell cycle, JM1 and K562 cells that had been treated with 10 or $20 \mu \mathrm{M} \mathrm{I3M}$ for 24 and $48 \mathrm{~h}$ were analyzed. Cell cycle analysis showed that I3M preferentially arrested JM1 and K562 cells in the G2/M phase (Fig. 2).

I3M induces apoptosis in JM1 and K562 cells. The increasing proportions of JM1 and K562 cells in the sub-G1 phase particularly indicated that I3M induced apoptotic cell death, which increased with time and concentration in both types of leukemia cells (Fig. 2). Since caspase-3 activation is involved in apoptosis, we next assessed the activation of caspase-3 in I3M-treated JM1 and K562 cells. Dose-dependent activation of caspase-3 was detected in both JM1 and K562 cell types
(Fig. 3A). In addition, I3M triggered the proteolytic cleavage of PARP-1, a signature event during apoptosis, particularly after $48 \mathrm{~h}$ in cells treated with 20 and $30 \mu \mathrm{M}$ of I3M (Fig. 3B). This suggests that I3M caused apoptosis. However, when we added the pan-caspase inhibitor Z-VAD-FMK to I3M-treated cell cultures, I3M-induced cell death was only partially inhibited (Fig. 3C).

I3M does not induce cell necrosis in JM1 or K562 cells. To clarify the data presented in Fig. 3C, we examined whether I3M induced a type of cell death other than apoptosis. Therefore, we analyzed the effect of I3M on cell necrosis. The results showed that even after a high dose of I3M $(35 \mu \mathrm{M})$, the amount of LDH released into the culture medium by JM1 and K562 cells was significantly lower than that released by the positive controls (Fig. 4).

I3M induces autophagic cell death in JM1 and K562 cells. We next investigated whether I3M induced autophagy. LC3-II formation dose-dependently increased in JM1 and K562 cells 24 and $48 \mathrm{~h}$ after treatment (Fig. 5); however, the expression of beclin-1, the other autophagy-related protein, did not.

I3M marginally induces cytotoxicity in primary lymphocytes, but not in primary granulocytes. Primary lymphocytes and granulocytes isolated from human peripheral blood were treated with the indicated concentrations of I3M. Cytotoxicity was evaluated using a WST-1 assay. The cell viability of primary lymphocytes treated with the $\mathrm{IC}_{50}$ value $(20 \mu \mathrm{M})$ of I3M were only marginally affected; $24-\mathrm{h}$ treatment was $73.9 \pm 5.1 \%$ and 48 -h treatment was $65.9 \pm 9.3 \%$ (Fig. 6A), and that of granulocytes was not significantly affected. Increasing the concentration of $\mathrm{I} 3 \mathrm{M}$ to $35 \mu \mathrm{M}$ and prolonging the treatment time to $48 \mathrm{~h}$ did not induce cell death (Fig. 6B). 
A
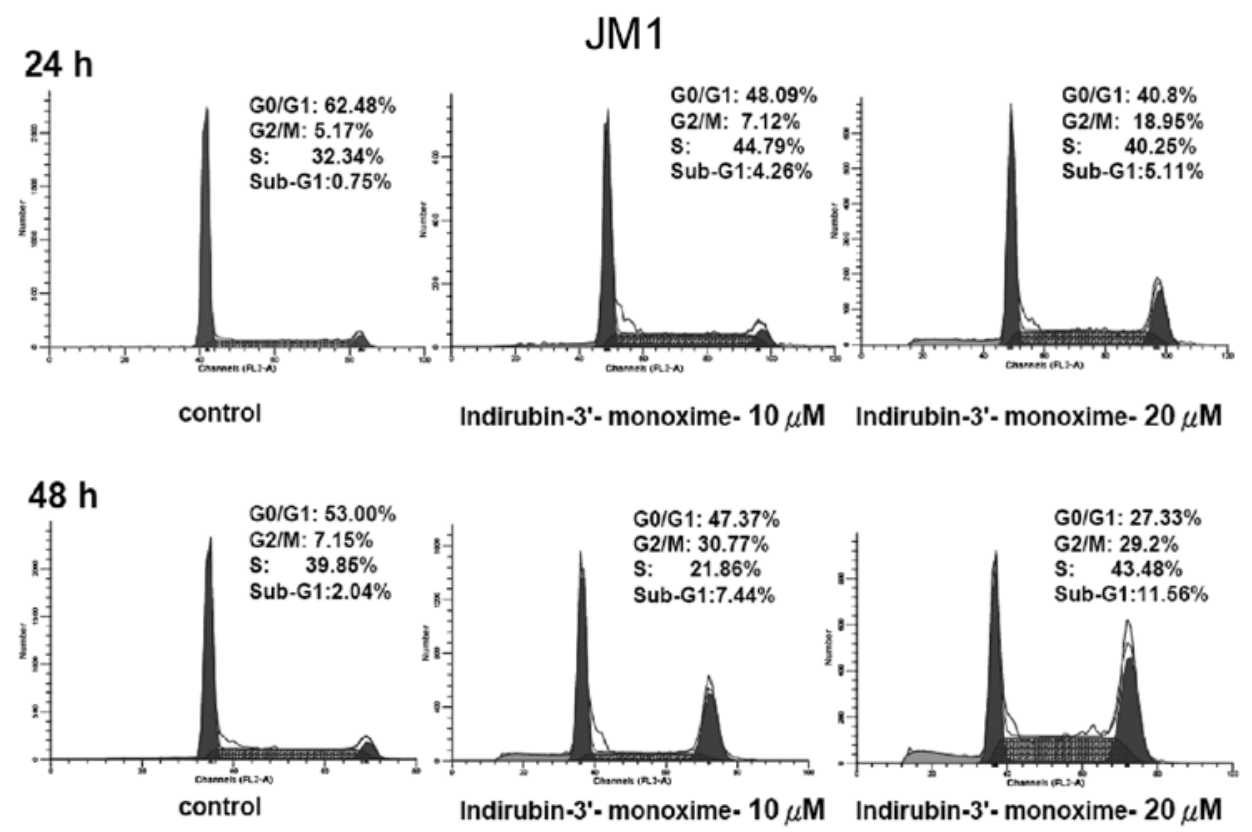

B

K562
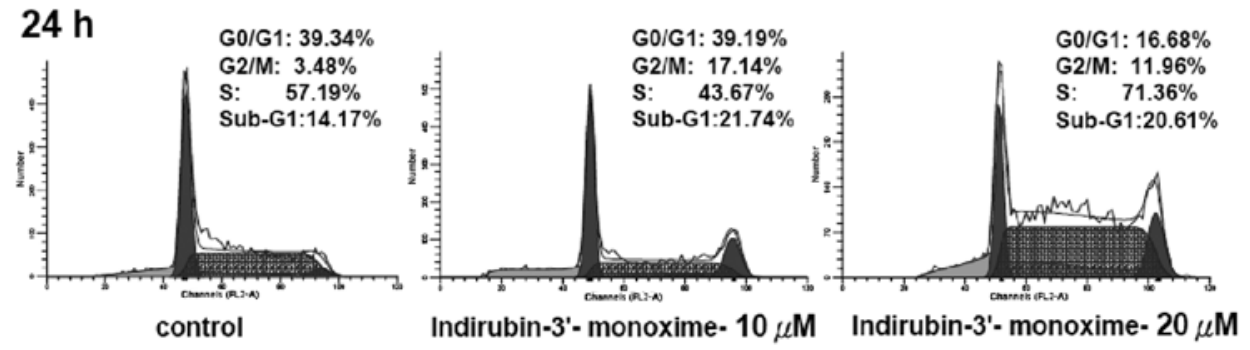

$48 \mathrm{~h}$
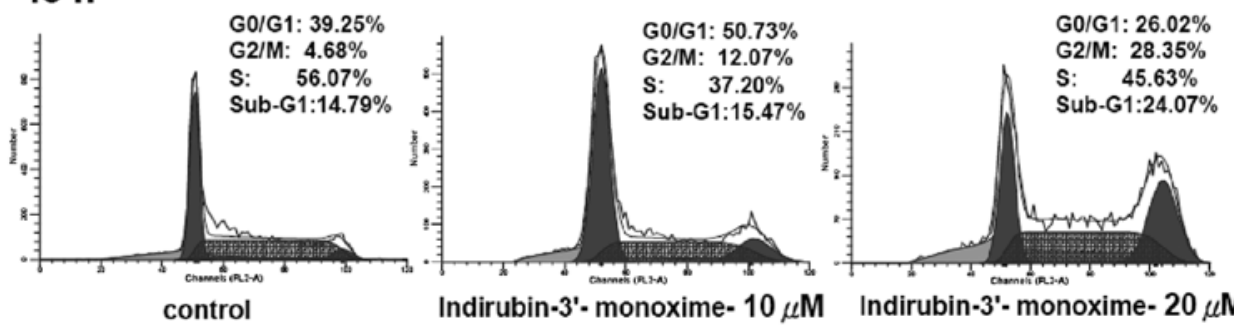

Figure 2. Cell cycle analysis of indirubin-3'-monoxime (I3M)-treated JM1 and K562 cells. (A) JM1 and (B) K562 cells were treated with I3M (10 or $20 \mu \mathrm{M})$ for 24 and $48 \mathrm{~h}$. Cell-cycle distribution analysis was performed using flow cytometry. One representative example is shown. This experiment was repeated separately four times.

\section{Discussion}

In the present study, we found that I3M dose-dependently increased cell death in human ALL JM1 cells and human CML K562 cells. These effects on cell viability included cellcycle arrest and the induction of apoptosis and autophagy.

Previous studies have shown that several indirubin derivatives lead to significant G2/M cell-cycle arrest. One study (4) reported that I3M suppressed K562 cell proliferation by inducing the arrest of cell development in the G2/M phase, which supports our observation that I3M significantly induced a G2/M phase arrest in JM1 and K562 cells. Moreover, the cellcycle results showed an increasing sub-G1 population, and, with the caspase- 3 activation, demonstrated a dose-dependent induction of apoptosis. In general, during apoptosis, caspase-3 activation leads to PARP fragmentation and cleavage. We also found PARP-1 cleavage in the present study. After using the pan-caspase inhibitor Z-VAD-FMK to block caspase activation, I3M-induced cell death was only slightly reduced. This suggested that, in addition to apoptosis, I3M induces cell death using other mechanisms as well.

There are at least three types of cell death: necrosis, apoptosis and autophagy (16). Most studies have indicated that indirubin induces apoptosis in diverse cancer cells. However, Ribas et al $(17,18)$ showed that 7-bromoindirubin-3'-oxime, an indirubin analog, triggered caspase-independent cell death, 
A

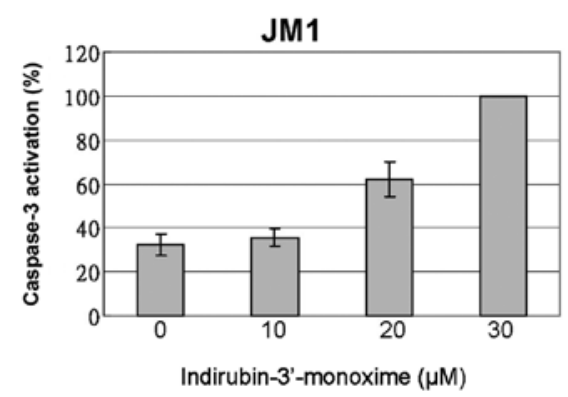

B

C

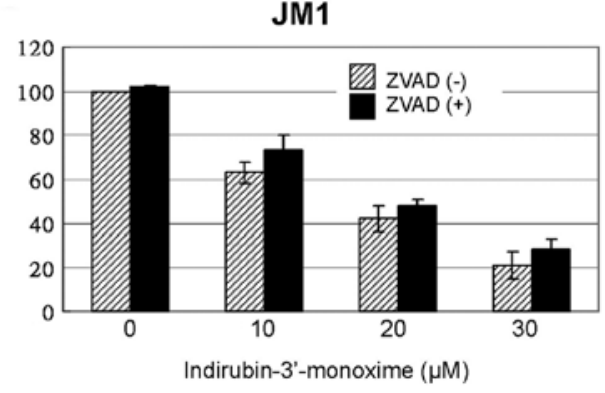

K562 (24 h)

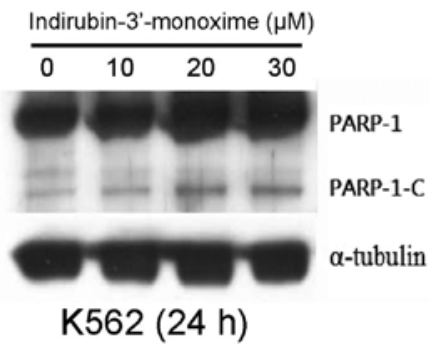

K562
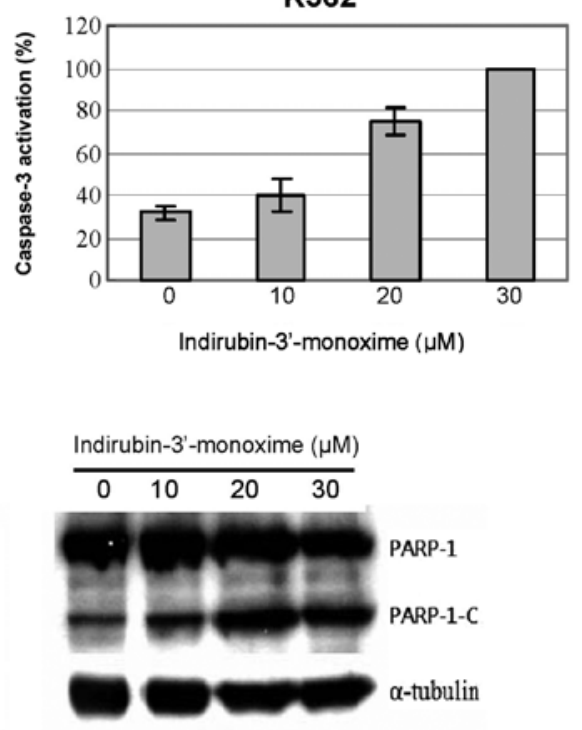

JM1 (48 h)

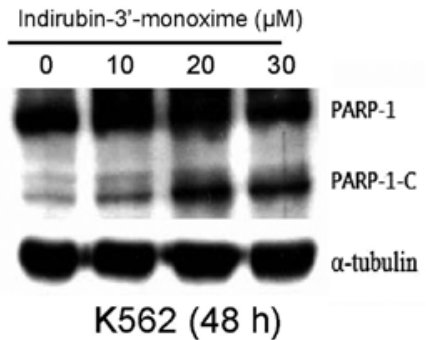

K562 (48 h)

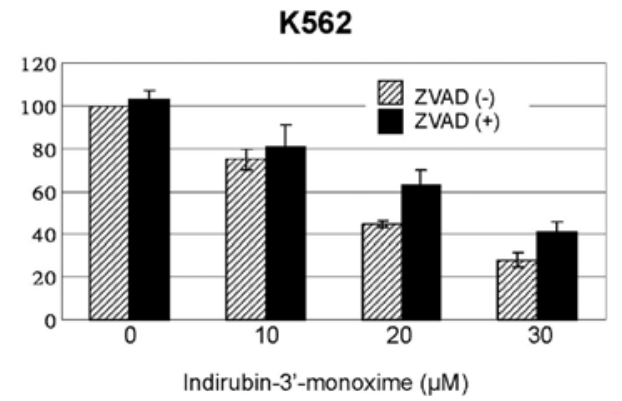

Figure 3. Apoptotic effect of indirubin-3'-monoxime (I3M) through caspase-3 activation in JM1 and K562 cells. JM1 and K562 cells were incubated with I3M $(0,10,20$ and $30 \mu \mathrm{M})$. (A) After $48 \mathrm{~h}$ of incubation, ELISA was used to test the activation of caspase-3. Untreated cells were controls. Data are the means \pm SD and are expressed as a percentage of the highest value $(=100 \%)(\mathrm{n}=6)$ (for all treatments with $\mathrm{I} 3 \mathrm{M}$ vs. untreated controls, $\mathrm{P}<0.05)$. (B) Following I3M treatment for 24 or $48 \mathrm{~h}$, the cells were harvested, whole cell lysates were subjected to immunoblot analysis with anti-PARP1/2 or anti- $\alpha$-tubulin. Blots shown are representative of three independent experiments. (C) Cells were incubated with or without Z-VAD-FMK for $1 \mathrm{~h}$ prior to I3M treatment. Cell viability was measured using a WST-1 assay. Data are the means \pm SD and are expressed as a percentage of control values (I3M and Z-VAD-FMK untreated cells, $100 \%)(\mathrm{n}=3)$.

i.e., a specific type of necrotic cell death. In the present study, however, we found that I3M did not induce necrotic cell death in leukemia cells.

Autophagy is caspase-independent programmed cell death (19). Microtubule-associated protein 1 light chain 3 (LC3), an autophagosomal ortholog of yeast Atg8, is a novel marker for autophagy. LC3-I is localized in the cytoplasm, whereas LC3-II aggregates on the membrane of autophagosomes $(20,21)$. Indeed, we found in I3M-treated ALL cells and CML cells the first evidence of the typical phenomenon of autophagy, i.e., significant upregulation of LC3-II formation.
Autophagy may trigger the upregulation of beclin-1, since beclin-1 is involved in the formation of autophagosomes (22). Compared with untreated cells, beclin-1 expression was not significantly upregulated in I3M-treated JM1 and K562 cells in the present study. Nonetheless, autophagy occurs independently of beclin-1 (23-26), which suggests that I3M-induced autophagy might also not affect beclin-1 expression. Future studies are required to confirm this hypothesis.

Patients with leukemia produce an abnormal number of leukocytes. When clinical therapy decreases the number of granulocytes and healthy lymphocytes in the blood, it often 
A
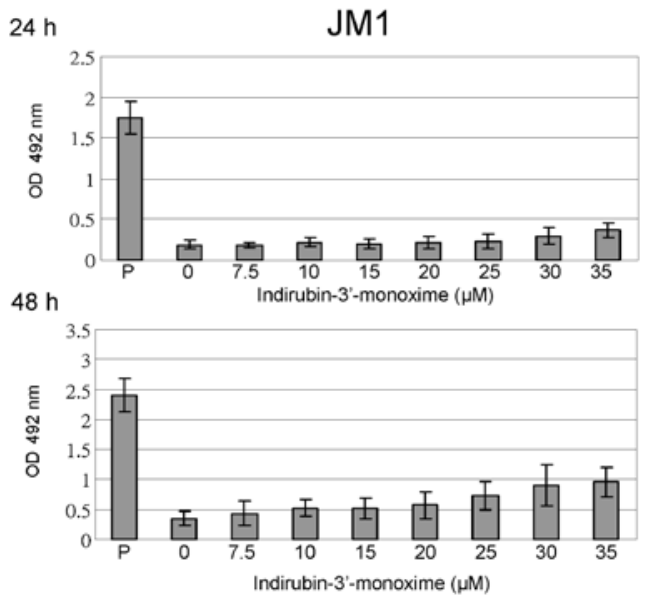

B
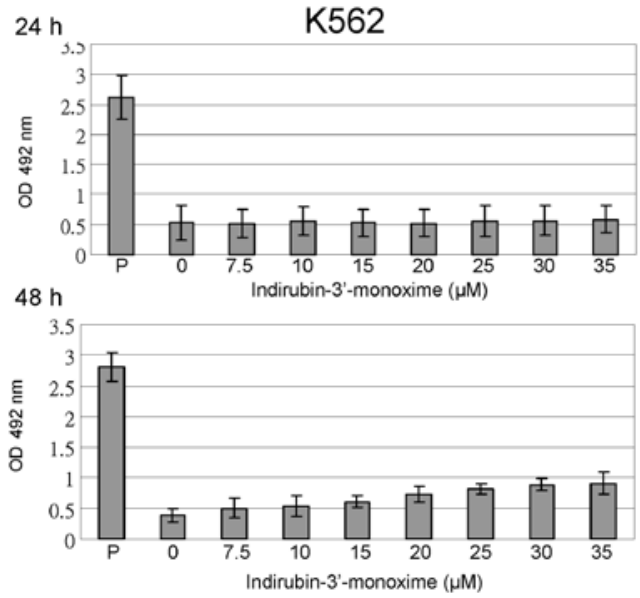

Figure 4. Analysis of the necrotic effect of indirubin-3'-monoxime (I3M) through LDH release in JM1 and K562 cells. (A) JM1 and (B) K562 cells were treated with various concentrations of I3M for 24 or $48 \mathrm{~h}$. Necrotic cell death was quantitatively measured using the release of LDH into the culture supernatants. The absorbance represents the amount of LDH measured at a wavelength of $492 \mathrm{~nm}$. Untreated cells were negative controls. The positive controls $(\mathrm{P})$ were obtained from the cells that had been treated with lysis solution for maximal LDH release. The data are the means \pm SD from six separate experiments per group. (All treatments vs. positive controls, $\mathrm{P}<0.05)$.

A

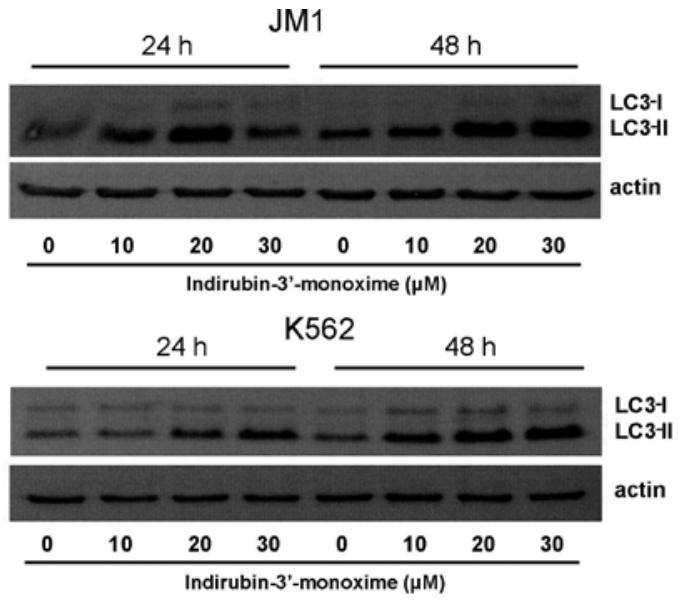

B
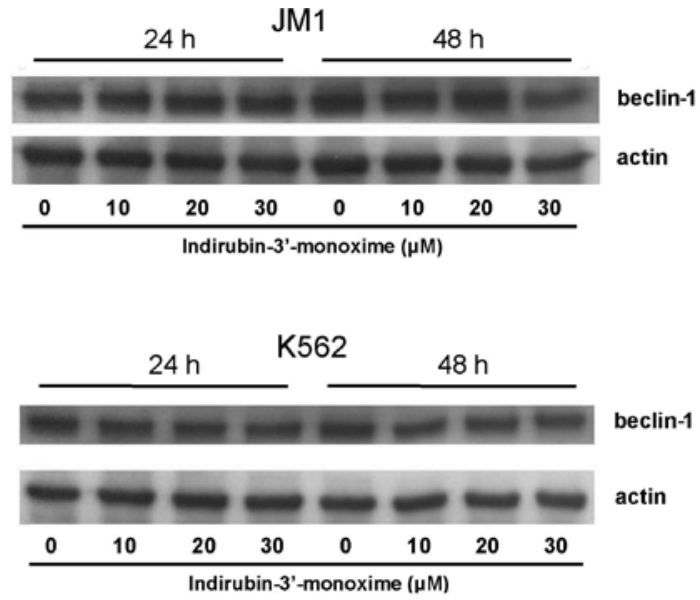

Figure 5. Detecting autophagy in indirubin-3'-monoxime (I3M)-treated JM1 and K562 cells. Expression of (A) LC3-II and (B) beclin-1 in I3M-treated K562 and JM1 cells. Cells were treated with or without various concentrations of I3M for 24 or $48 \mathrm{~h}$. Whole cell lysates were collected and analyzed using western blotting with antibodies against LC3 or beclin-1. One representative example is shown from four repeated experiments.

A $\quad 24 \mathrm{~h}$

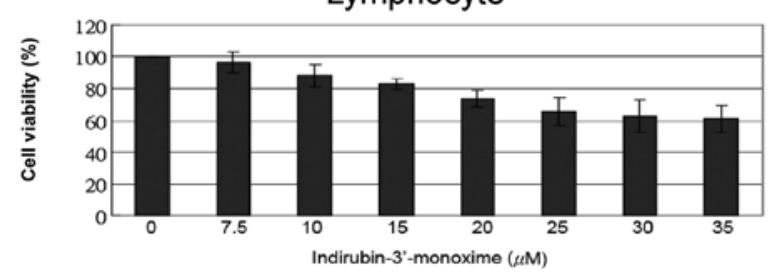

$48 \mathrm{~h}$

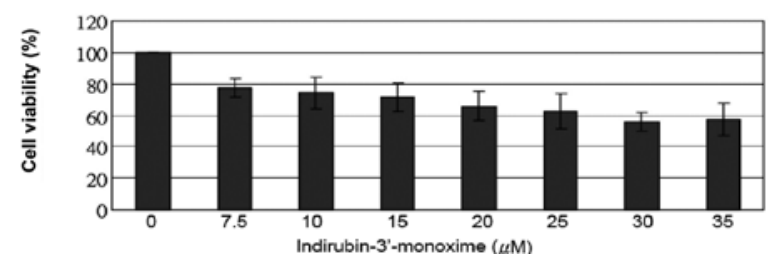

B

$24 \mathrm{~h}$
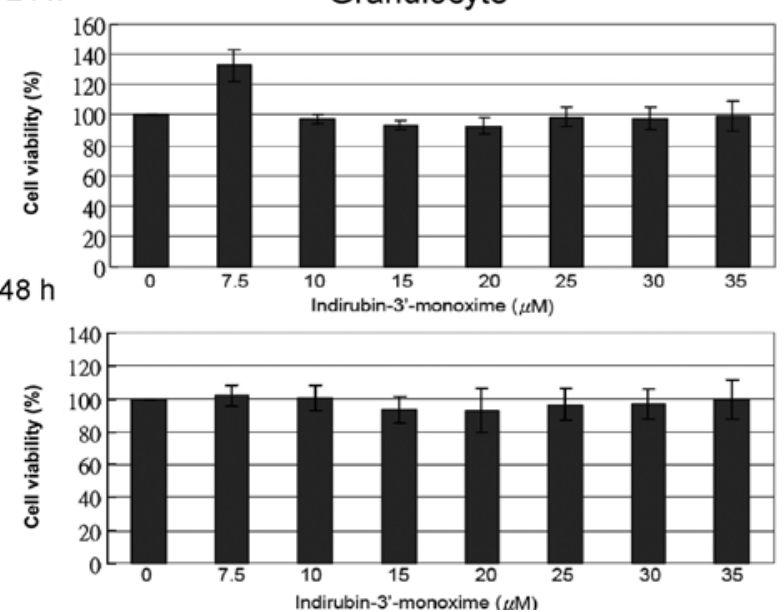

Figure 6. Cytotoxicity of indirubin-3'-monoxime (I3M) on lymphocytes and granulocytes. (A) Primary lymphocytes isolated from the buffy coat of healthy donors $(\mathrm{n}=10)$ and $(B)$ primary granulocytes isolated from the buffy coat of healthy donors $(\mathrm{n}=9)$ were treated with various concentrations of $\mathrm{I} 3 \mathrm{M}$ for 24 or $48 \mathrm{~h}$. Untreated cells were controls. Cell viability was assessed using a WST-1 assay. Cell viability is expressed as a percentage of population growth with the standard error of the mean relative to that of untreated control cells $(\mathrm{I} 3 \mathrm{M}$-untreated cells $=100 \%)$. The difference between the I3M-treated granulocytes and untreated controls was not significant, and the difference was only borderline significant between the I3M-treated lymphocytes and controls. 
leads to serious infection and mortality. Therefore, clinical cancer therapy must be as non-cytotoxic as possible to healthy leukocytes, particularly for leukemia therapy. PHA-stimulated peripheral blood lymphocytes are dose-dependently sensitive to I3M treatment (27); however, I3M is cytotoxic to unstimulated lymphocytes only in high doses. These data do not conflict with our findings. Consequently, lymphocyte viability was only marginally affected in the present study. Due to their innate immunity, granulocytes are central in defending the host from infection by other organisms. This is the first study of the effects of I3M on healthy primary granulocytes. The dose of I3M that we used had no cytotoxic effect on granulocytes.

In conclusion, we showed that I3M was cytotoxic to K562 and JM1 cells, and that it had no significant effect on the cell viability of primary lymphocytes and granulocytes. This finding might provide a first step for clinical trials with lowlevel side-effects in ALL treatment.

\section{Acknowledgements}

The authors thank the Tainan Blood Center, Taiwan Blood Services Foundation, for providing buffy coats. This study was supported by grant R96-11 from the Ditmanson Medical Foundation Chia-Yi Christian Hospital Research Program.

\section{References}

1. Pui $\mathrm{CH}$ and Evans WE: Treatment of acute lymphoblastic leukemia. N Engl J Med 354: 166-178, 2006.

2. Fielding AK, Richards SM, Chopra R, et al: Outcome of 609 adults after relapse of acute lymphoblastic leukemia (ALL); an MRC UKALL12/ECOG 2993 study. Blood 109: 944-950, 2007.

3. Tavernier E, Boiron JM, Huguet F, et al: Outcome of treatment after first relapse in adults with acute lymphoblastic leukemia initially treated by the LALA-94 trial. Leukemia 21: 1907-1914, 2007.

4. Hoessel R, Leclerc S, Endicott JA, et al: Indirubin, the active constituent of a Chinese antileukemia medicine, inhibits cyclindependent kinases. Nat Cell Biol 1: 60-67, 1999.

5. Institute of Haematology, Chinese Academy of Medical Sciences: Experimental and clinical studies of indirubin in the treatment of CML. Chinese J Intern Med 18: 83-88, 1979.

6. Cooperative Group of Clinical Therapy of Indirubin: Clinical studies of 314 cases of CML treated with indirubin. Chinese $\mathrm{J}$ Intern Med 1: 132-135, 1980.

7. Marko D, Schatzle S, Friedel A, Genzlinger A, Zankl H, Meijer L and Eisenbrand G: Inhibition of cyclin-dependent kinase 1 (CDK1) by indirubin derivatives in human tumour cells. Br J Cancer 84: 283-289, 2001.

8. Jautelat R, Brumby T, Schäfer M, Briem H, Eisenbrand G, Schwahn S, Krüger M, Lücking U, Prien O and Siemeister G: From the insoluble dye indirubin towards highly active, soluble CDK2-inhibitors. Chembiochem 6: 531-540, 2005.

9. Kim SA, Kim SW, Chang S, Yoon JH and Ahn SG: 5'-nitroindirubinoxime induces $\mathrm{G} 2 / \mathrm{M}$ cell cycle arrest and apoptosis in human KB oral carcinoma cells. Cancer Lett 274: 72-77, 2009.

10. Yoon JH, Kim SA, Kwon SM, Park JH, Park HS, Kim YC, Yoon JH and Ahn SG: 5'-Nitro-indirubinoxime induces G1 cell cycle arrest and apoptosis in salivary gland adenocarcinoma cells through the inhibition of Notch-1 signaling. Biochim Biophys Acta 1800: 352-358, 2010.
11. Shi R, Li W, Zhang X, Zhang Y, Peng H, Xie Y, Fan D, Liu R, Liu X and Xiong D: A novel indirubin derivative PHII-7 potentiates adriamycin cytotoxicity via inhibiting P-glycoprotein expression in human breast cancer MCF-7/ADR cells. Eur J Pharmacol 669: 38-44, 2011.

12. Kunz M, Driller KM, Hein M, Hohensee I, Ramer R, Hinz B, Berger A, Eberle J and Langer P: Synthesis of thia-analogous indirubin $\mathrm{N}$-Glycosides and their influence on melanoma cell growth and apoptosis. ChemMedChem 5: 534-539, 2010.

13. Berger A, Quast SA, Plötz M, Hein M, Kunz M, Langer P and Eberle J: Sensitization of melanoma cells for death ligandinduced apoptosis by an indirubin derivative. Enhancement of both extrinsic and intrinsic apoptosis pathways. Biochem Pharmacol 81: 71-81, 2011.

14. Kameswaran TR and Ramanibai R: Indirubin-3-monooxime induced cell cycle arrest and apoptosis in Hep-2 human laryngeal carcinoma cells. Biomed Pharmacother 63: 146-154, 2009.

15. Suzuki K, Adachi R, Hirayama A, Watanabe H, Otani S, Watanabe Y and Kasahara T: Indirubin, a Chinese anti-leukaemia drug, promotes neutrophilic differentiation of human myelocytic leukemia HL-60 cells. Br J Haematol 130: 681-690, 2005.

16. Okada $\mathrm{H}$ and Mak TW: Pathways of apoptotic and non-apoptotic death in tumour cells. Nat Rev Cancer 4: 592-603, 2004.

17. Ribas J, Bettayeb K, Ferandin Y, et al: 7-Bromoindirubin-3'oxime induces caspase-independent cell death. Oncogene 25: 6304-6318, 2006.

18. Ribas J, Yuste VJ, Garrofé-Ochoa X, Meijer L, Esquerda JE and Boix J: 7-Bromoindirubin-3'-oxime uncovers a serine proteasemediated paradigm of necrotic cell death. Biochem Pharmacol 76: 39-52, 2008.

19. Kondo Y, Kanzawa T, Sawaya R and Kondo S: The role of autophagy in cancer development and response to therapy. Nat Rev Cancer 5: 726-734, 2005

20. Yoshioka A, Miyata H, Doki Y, Yamasaki M, Sohma I, Gotoh K, Takiguchi S, Fujiwara Y, Uchiyama Y and Monden M: LC3, an autophagosome marker, is highly expressed in gastrointestinal cancers. Int J Oncol 33: 461-468, 2008.

21. Kabeya Y, Mizushima N, Ueno T, Yamamoto A, Kirisako T, Noda T, Kominami E, Ohsumi Y and Yoshimori T: LC3, a mammalian homologue of yeast Apg8p, is localized in autophagosome membranes after processing. EMBO J 19: 5720-5728, 2000.

22. Wang J: Beclin 1 bridges autophagy, apoptosis and differentiation. Autophagy 4: 947-948, 2008.

23. Zhu JH, Horbinski C, Guo F, Watkins S, Uchiyama Y and Chu CT: Regulation of autophagy by extracellular signal-regulated protein kinases during 1-methyl-4-phenylpyridinium-induced cell death. Am J Pathol 170: 75-86, 2007.

24. Kim I, Rodriguez-Enriquez S and Lemasters JJ: Selective degradation of mitochondria by mitophagy. Arch Biochem Biophys 462: 245-253, 2007.

25. Mordier S, Deval C, Béchet D, Tassa A and Ferrara M: Leucine limitation induces autophagy and activation of lysosomedependent proteolysis in $\mathrm{C} 2 \mathrm{C} 12$ myotubes through a mammalian target of rapamycin-dependent signaling pathway. J Biol Chem 275: 29900-29906, 2000

26. Kanazawa T, Taneike I, Akaishi R, Yoshizawa F, Furuya N, Fujimura $S$ and Kadowaki M: Amino acids and insulin control autophagic proteolysis through different signaling pathways in relation to mTOR in isolated rat hepatocytes. J Biol Chem 279: 8452-8459, 2004

27. Kagialis-Girard S, Mialou V, Chebel A, Chien WW, Tigaud I, Mokdad F, Badiou C and Ffrench M: Inhibition of normal lymphocyte proliferation by indirubin-3'-monoxime: a multifactorial process. Leuk Lymphoma 48: 605-615, 2007. 